\title{
THE UNWVERSITY of WARWICK
}

Original citation:

Ragazzon, Giulio, Bratsos, Ioannis, Alessio, Enzo, Salassa, Luca, Habtemariam, Abraha, McQuitty, Ruth J., Clarkson, Guy J. and Sadler, Peter J.. (2012) Design of photoactivatable metallodrugs : Selective and rapid light-induced ligand dissociation from half-sandwich $\left[\mathrm{Ru}([9] \mathrm{aneS} 3)\left(\mathrm{N}-\mathrm{N}^{\prime}\right)(\mathrm{py})\right] 2+$ complexes. Inorganica Chimica Acta, Vol.393. pp. 230-238

Permanent WRAP url:

http://wrap.warwick.ac.uk/53172

\section{Copyright and reuse:}

The Warwick Research Archive Portal (WRAP) makes the work of researchers of the University of Warwick available open access under the following conditions. Copyright (C) and all moral rights to the version of the paper presented here belong to the individual author(s) and/or other copyright owners. To the extent reasonable and practicable the material made available in WRAP has been checked for eligibility before being made available.

Copies of full items can be used for personal research or study, educational, or not-forprofit purposes without prior permission or charge. Provided that the authors, title and full bibliographic details are credited, a hyperlink and/or URL is given for the original metadata page and the content is not changed in any way.

\section{Publisher's statement:}

"NOTICE: this is the author's version of a work that was accepted for publication in Inorganica Chimica Acta.Changes resulting from the publishing process, such as peer review, editing, corrections, structural formatting, and other quality control mechanisms may not be reflected in this document. Changes may have been made to this work since it was submitted for publication. A definitive version was subsequently published in Inorganica Chimica Acta, Vol.393. pp. 230-238.

http://dx.doi.org/10.1016/j.ica.2012.06.031

\section{A note on versions:}

The version presented here may differ from the published version or, version of record, if you wish to cite this item you are advised to consult the publisher's version. Please see the 'permanent WRAP url' above for details on accessing the published version and note that access may require a subscription.

For more information, please contact the WRAP Team at: wrap@warwick.ac.uk

$$
\text { warwickpublicationswrap }
$$

highlight your research 
For submission to ICA (Special Issue on Metals in Medicine)

\title{
Design of Photoactivatable Metallodrugs: Selective and Rapid Light-induced Ligand Dissociation from Half- Sandwich $\left[\operatorname{Ru}\left([9] \operatorname{aneS}_{3}\right)\left(\mathbf{N}-\mathbf{N}^{\prime}\right)(\mathrm{py})\right]^{2+}$ Complexes
}

Giulio Ragazzon, ${ }^{a}$ Ioannis Bratsos, ${ }^{a}$ Enzo Alessio $*^{a}$

Luca Salassa, $*^{b}$ Abraha Habtemariam, ${ }^{b}$ Ruth J. McQuitty, ${ }^{b}$ Guy J. Clarkson ${ }^{b}$ and Peter J. Sadler*b

${ }^{a}$ Dipartimento di Scienze Chimiche e Farmaceutiche, Università di Trieste, 34127 Trieste (Italy)

${ }^{b}$ Department of Chemistry, University of Warwick, Gibbet Hill Road, Coventry CV4 7AL $(U K)$

Keywords ruthenium, photochemistry, macrocycle, coordination complex, pyridine ligand, bioinorganic

\begin{abstract}
The synthesis of the inert $\mathrm{Ru}(\mathrm{II})$ half-sandwich coordination compounds, $\left[\mathrm{Ru}\left([9] \mathrm{aneS}_{3}\right)(\mathrm{bpy})(\mathrm{py})\right]\left[\mathrm{PF}_{6}\right]_{2} \quad\left(\mathbf{1}, \quad[9] \mathrm{aneS}_{3} \quad=\quad\right.$ 1,4,7-trithiacyclononane $)$, $\left[\mathrm{Ru}\left([9] \mathrm{aneS}_{3}\right)(\mathrm{en})(\mathrm{py})\right]\left[\mathrm{PF}_{6}\right]_{2}\left(\mathbf{2}\right.$, en = 1,2-diaminoethane), and $\left[\mathrm{Ru}\left([9] \mathrm{aneN} \mathrm{N}_{3}\right)(\mathrm{en})\left(\mathrm{dmso}^{-}\right.\right.$ $\mathrm{S})]\left[\mathrm{PF}_{6}\right]_{2}\left(3,[9] \mathrm{aneN}_{3}=1,4,7\right.$-triazacyclononane), is reported along with the X-ray crystal structure of $\mathbf{1}$. We investigated whether these complexes have photochemical properties which might make them suitable for use as pro-drugs in photochemotherapy. Complexes 1 and $\mathbf{2}$ underwent rapid (minutes) aquation with dissociation of the pyridine ligand in aqueous solution when irradiated with blue light $(\lambda=420$ or $467 \mathrm{~nm})$. The photodecompostion of $\mathbf{3}$ was much slower. All complexes readily formed adducts with 9ethylguanine (9-EtG) when this model nucleobase was present in the photolysis solution. Similarly, complex 1 formed adducts with the tripeptide glutathione (GSH), but only when photoactivated. HPLC-MS studies of 1 showed that irradiation promoted rapid formation of 1:1 (major) and 1:2 (minor) adducts of the oligonucleotide d(ATACATGCTACATA) with the fragment $\left\{\mathrm{Ru}\left([9] \mathrm{aneS}_{3}\right)(\mathrm{bpy})\right\}^{2+}$. Density functional theory (DFT) calculations and time-dependent DFT reproduced the major features of the absorption spectra and suggested that the lowest-lying triplet state with ${ }^{3}$ MLCT character, which is readily accessible via intersystem crossing, might be responsible for the
\end{abstract}


observed dissociative behaviour of the excited states. These complexes are promising for further study as potential photochemotherapeutic agents.

\section{Introduction}

Typically, anticancer metal compounds show non-specific toxicity, not limited to tumor cells. A strategy for overcoming this disadvantage would be a rational design that involves their selective activation. In this approach a non-toxic precursor of the active species is administered, and activated exclusively in the tumor region. Provided that activation occurs selectively, this strategy would have the clear advantage of limiting the undesired effects of the drug, thus increasing its therapeutic index. In ideal conditions, even if the prodrug distributes equally in the body, only the part activated at the tumor site would be highly cytotoxic. The use of light for activating an anticancer compound is one of the strategies that is being investigated, and for this reason is termed photoactivated chemotherapy (PACT) [1] The effective wavelength range of light in photobiological and phototherapeutic processes is between 300 and $900 \mathrm{~nm}$. Shorter wavelengths (UVA, blue light) would be effective only for surface cancers whereas longer wavelengths (e.g. red light) penetrate more deeply [2].

One potential objective in the context of PACT is the development of complexes capable of killing cancer cells by binding to DNA as a target. This might occur upon photoinduced dissociation of one or more ligands from the coordination sphere of the metal. The irradiation of the tumor site with a light source would lead to the release of active metal fragments directly into cancer cells [3].

After developing a large series of anticancer $\mathrm{Ru}(\mathrm{II})$-arene organometallic compounds, whose mechanism of action is believed to involve monofunctional coordination to DNA after the hydrolysis of a labile monodentate ligand (e.g. $\mathrm{Cl}^{-}$from $\left[\left(\eta^{6} \text {-arene }\right) \mathrm{Ru}(\mathrm{en}) \mathrm{Cl}\right]^{+}$, en = 1,2-diaminoethane) [4], Sadler and co-workers have demonstrated that irradiation of inert half-sandwich $\mathrm{Ru}(\mathrm{II})$ compounds of the type $\left[\left(\eta^{6} \text {-arene) } \mathrm{Ru}(N-N)(\mathrm{L})\right]^{2+}\right.$ (where $N-N$ is a nitrogen chelating ligand, $\mathrm{L}$ is typically a nitrogen monodentate ligand such as pyridine) with visible light leads to the selective dissociation of the monodentate ligand (i.e. activation). For example, the complex $\left[\left(\eta^{6}-p\right.\right.$-cymene $\left.) \mathrm{Ru}(\mathrm{bpm})(\mathrm{py})\right]\left[\mathrm{PF}_{6}\right](\mathrm{bpm}=$ 2,2'-bipyrimidine, $\mathrm{py}=$ pyridine) is inert in aqueous solution over a wide range of $\mathrm{pH}$ values (2-12) if kept in the dark. However, upon irradiation with visible light the complex releases selectively the pyridine ligand generating the active aqua species $\left[\left(\eta^{6}-p\right.\right.$ cymene $\left.) \mathrm{Ru}(\mathrm{bpm})\left(\mathrm{H}_{2} \mathrm{O}\right)\right]^{2+}$ which is capable of binding to DNA model bases such as 9ethylguanine [5].

On the other hand Alessio and co-workers have demonstrated that the formal replacement of the arene ligand in half-sandwich complexes with a neutral face-capping tridentate macrocycle (e.g. 1,4,7-trithiacyclononane, [9]ane $\mathrm{S}_{3}$ ) leads to half-sandwich coordination compounds that maintain in vitro cytotoxic activity against cancer cells provided that they undergo aquation with substitution of the monodentate ligand at a reasonable rate and that the chelate ligand is a hydrogen-bond donor. Thus $\left[\mathrm{Ru}\left([9] \mathrm{aneS}_{3}\right)(\mathrm{en}) \mathrm{Cl}\right]\left[\mathrm{PF}_{6}\right]$ 
and $\left[\mathrm{Ru}\left([9] \mathrm{ane} \mathrm{S}_{3}\right) \mathrm{Cl}(\mathrm{dach})\right]\left[\mathrm{PF}_{6}\right]$ (dach = 1,2-diaminocyclohexane), that fulfill both requirements, show cytotoxic activity comparable to their organometallic analogues.

Given such premises, the purpose of this work was to investigate the photochemistry of selected inert $\mathrm{Ru}(\mathrm{II})$ half-sandwich coordination compounds, namely $\left[\mathrm{Ru}\left([9] \mathrm{aneS}_{3}\right)(\mathrm{bpy})(\mathrm{py})\right]\left[\mathrm{PF}_{6}\right]_{2} \quad(\mathbf{1}), \quad\left[\mathrm{Ru}\left([9] \mathrm{aneS}_{3}\right)(\mathrm{en})(\mathrm{py})\right]\left[\mathrm{PF}_{6}\right]_{2} \quad$ (2), $\quad$ and $\left[\mathrm{Ru}\left([9] \mathrm{aneN}_{3}\right)(\mathrm{en})\left(\mathrm{dmso}^{\mathrm{S}}\right)\right]\left[\mathrm{PF}_{6}\right]_{2}\left(\mathbf{3},[9] \mathrm{aneN}_{3}=1,4,7\right.$-triazacyclononane $)($ Chart 1$)$ that are structurally similar to the photoactivable anticancer organometallic compounds developed by Sadler and co-workers. More specifically, we wanted to assess the rate and extent of dissociation of the monodentate ligand upon irradiation with visible light and the capability of the resulting aqua-species to interact with selected biomolecules. To obtain a deeper understanding of the photochemical processes which occur, DFT and TDDFT calculations were also performed.

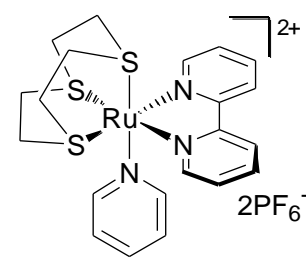

(1)

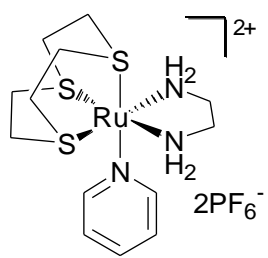

(2)

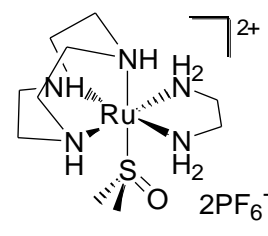

(3)

Chart 1

\section{Experimental}

\subsection{Materials and methods}

Silver nitrate, methanol, $\mathrm{NH}_{4} \mathrm{PF}_{6}, \mathrm{D}_{2} \mathrm{O}$, 9-ethylguanine (9-EtG) and L-glutathione reduced $(\mathrm{GSH})$ were purchased from Sigma-Aldrich, pyridine from Fluka and $\mathrm{NaH}_{2} \mathrm{PO}_{4}$, $\mathrm{Na}_{2} \mathrm{HPO}_{4}$ and acetone from Fisher Chemicals. The PBS buffer was prepared in $\mathrm{D}_{2} \mathrm{O}$ with a concentration of $0.1 \mathrm{M}$ and $\mathrm{pH}$ 7.2. The single strand oligonucleotide d(ATACATGCTACATA) was purchased from DNA Technology A/S (Denmark), purified twice by RP-HPLC and contains sodium as the counter ion. HPLC mobile phase: HPLC grade $\mathrm{CH}_{3} \mathrm{CN}$ and $\mathrm{H}_{2} \mathrm{O}$ were purchased from Fisher Scientific. Ammonium acetate (99.99\%) was purchased from Sigma-Aldrich. All samples were prepared in doubly deionised water purified using Multipore Milli Q and a USF-Elga UHQ water deioniser. Omix pipette tips for micro extraction were purchased from Varian Inc.

\subsubsection{NMR spectroscopy}

NMR spectra were acquired in $5 \mathrm{~mm}$ NMR tubes at $298 \mathrm{~K}$ on either Bruker DRX-500, Bruker AV III 600 or Bruker AV II 700 NMR spectrometers. All data processing was carried out using XWIN-NMR version 3.6 (Bruker U.K. Ltd.). ${ }^{1} \mathrm{H}$-chemical shifts were internally referenced to TMS via 1,4 -dioxane $(\delta=3.71)$. 1D spectra were recorded using standard pulse sequences. Typically, data were acquired with 128 transients into 16k data points over a spectral width of $14 \mathrm{ppm}$. 2D COSY and NOESY spectra were recorded using standard pulse-pulse sequences. For NOESY spectra, data were acquired with 72 
transients into 2048 data points over a spectral width of $14 \mathrm{ppm}$ using a relaxation delay of $1.5 \mathrm{~s}$ and a mixing time of $0.4-0.6 \mathrm{~s}$.

\subsubsection{Mass spectrometry}

Positive ion electrospray mass spectrometry ESI(+) was performed on an Esquire2000 Mass Spectrometer (Bruker, Coventry, UK Ltd). All data were acquired and processed with Bruker MicroTOF control Bruker Compas DataAnalysis (version 4.0) and OriginPro8.1. Mass spectrometry work with the d(ATACATGCTACATA) oligonucleotide was carried out on a Bruker MaXis ESI-HR-MS in the negative mode $(290-5000 \mathrm{~m} / \mathrm{z}$ scan range), capillary $4000 \mathrm{~V}$, end plate offset $-500 \mathrm{~V}$, dry gas $4.0 \mathrm{~L} / \mathrm{min}$, dry heater $180^{\circ} \mathrm{C}$, nebuliser 0.4 bar.

\subsubsection{UV-Visible spectroscopy}

UV-vis absorption spectra were recorded on a Cary 300-spectrophotometer using 1-cm pathlength quartz cuvettes $(600 \mu \mathrm{L})$ and a PTP1 Peltier temperature controller. Spectra were recorded at $310 \mathrm{~K}$ in deionized water from 200 to $800 \mathrm{~nm}$ and were processed using Cary WinUV software for Windows XP and OriginPro8.1.

\subsubsection{HPLC}

HPLC studies were carried out on an Agilent Technologies 1100 system with a Rheodyne 7725 i manual injector fitted with a $100 \mu \mathrm{L}$ loop and a DAD UV-Vis detector. The mobile phase for all analyses was solvent $\mathrm{A}: \mathrm{H}_{2} \mathrm{O} 10 \mathrm{mM} \mathrm{NH} \mathrm{HAc}_{4} \mathrm{OHH}$ 5.5); solvent $\mathrm{B}: \mathrm{CH}_{3} \mathrm{CN}$, $10 \mathrm{mM} \mathrm{NH}_{4} \mathrm{OAc}$. The column used was a Hichrom ACE 5 C8 $250 \times 4.6 \mathrm{~mm} 300 \AA$ pore size. At all times the flow rate was $1 \mathrm{~mL} / \mathrm{min}$, the wavelength of detection was set to 260 $\mathrm{nm}$ and the column oven was between $308 \mathrm{~K}$ and $313 \mathrm{~K}$. Solvent gradient was as follows: increasing 0-20\% B over $40 \mathrm{~min}$, followed by $20-80 \% \mathrm{~B}$ over $40-41 \mathrm{~min}$, and between $40-45$ min remaining at $80 \% \mathrm{~B}$.

\subsubsection{Photoirradiation of 1-3 in aqueous solution and in the presence of 9-ethylguanine and L-glutathione}

Photochemistry studies were performed by irradiating aqueous solutions of complexes 13 as well as buffered solutions (PBS) of the complexes and 9-ethylguanine (9-EtG) in a 1:1 mixture. In the case of complex 1, PBS solutions containing L-glutathione (GSH) (1:1 mixture) were also irradiated with blue light. As light source, a broadband visible light lamp (16 tubes, model LZC420; Luzchem research inc., Ottawa, Canada), operating with a maximum output at $420 \mathrm{~nm}$ and a maximum power of $c a .20 \mathrm{~mW} / \mathrm{cm}^{2}$ was used. Excitation at $467 \mathrm{~nm}$ and $517 \mathrm{~nm}$ was performed using LED sources (Philips Accent Color GU10). UV-Vis absorption spectra were recorded at a100 $\mu \mathrm{M}$ concentration using 
a reduced irradiation power of $7 \mathrm{~mW} / \mathrm{cm}^{2}$, while ${ }^{1} \mathrm{H}-\mathrm{NMR}$ spectra were recorded for 3 $\mathrm{mM}$ solutions using the full light output. Solutions were stored in the dark to minimize unwanted photoreactions between measurements. Irradiation experiments in the presence of GSH were performed in an inert nitrogen atmosphere.

\subsubsection{Photoirradiation of 1 in the presence of oligonucleotides}

Compound 1 was dissolved in water and mixed with the oligonucleotide $\mathrm{d}$ (ATACATGCTACATA) in a 1:1 mol ratio (final concentration of $250 \mu \mathrm{M}$ ). The concentration of 1 was determined by ICP-MS and the oligonucleotide by UV-Vis spectroscopy. The reaction was monitored by HPLC and mass spectrometry. The solution was irradiated in a Luzchem photoreactor fitted with $420 \mathrm{~nm}$ bulbs, with a power of $c a$. $20 \mathrm{~mW} / \mathrm{cm}^{2}$, at $310 \mathrm{~K}$ for a total of $2 \mathrm{~h}$ with aliquots taken every $30 \mathrm{~min}$ starting at time 0 (non-irradiated sample). Each aliquot was then further diluted in doubly-deionised water and analysed by HPLC. For MS analysis $400 \mu \mathrm{L}$ of the solution irradiated for a total of 2 $\mathrm{h}$ was de-salted using Omix micro extraction C18 pipette tips and eluted in $40 \mathrm{mM}$ ammonium acetate $\left(60: 40 \mathrm{CH}_{3} \mathrm{CN}: \mathrm{H}_{2} \mathrm{O}\right)$.

\subsubsection{Computational details}

All calculations on complex 1 were performed with Gaussian03 [6], employing the DFT method with the PBE1PBE functional [7]. The LanL2DZ effective core potential [8] was used for the $\mathrm{Ru}$ atom and the $6-31 \mathrm{G}^{* *}+$ basis set [9] was used for all other atoms. Geometry optimization of the singlet ground state and the lowest-lying triplet state was performed in the gas phase. The nature of the stationary points was confirmed by normal mode analysis. The conductor-like polarizable continuum model method (CPCM) [10] with water as solvent was used to calculate the electronic structure of the excited states of the complexes in solution $\left(\mathrm{H}_{2} \mathrm{O}\right)$. Fifty singlet excited states and eight triplet excited states, as well as the corresponding oscillator strength, were determined with TD-DFT calculation [11] using the singlet ground state and the lowest-lying triplet state geometries, respectively. The electronic distribution and the localization of the singlet and triplet excited states were visualized using the electron density difference maps (EDDMs) [12]. GaussSum 1.05 [13] was used for EDDMs calculations and for the electronic spectrum simulation. A summary of the calculated electronic transitions is reported in the Supporting Information. Molecular graphics images were produced using the UCSF Chimera package from the Resource for Biocomputing, Visualization, and Informatics at the University of California, San Francisco (supported by NIH P41 RR001081) [14].

\subsection{Synthesis and characterization of compounds}

The procedure for obtaining the precursor complex $\left[\mathrm{Ru}\left([9] \mathrm{aneS}_{3}\right)(\mathrm{bpy}) \mathrm{Cl}\right]\left[\mathrm{PF}_{6}\right]$ is similar to that previously described for the corresponding $\mathrm{CF}_{3} \mathrm{SO}_{3}$ compound [15]. To 
$\left[\mathrm{Ru}\left([9] \mathrm{aneS}_{3}\right)\left(\mathrm{dmso}^{\mathrm{S}}\right)_{2} \mathrm{Cl}\right]\left[\mathrm{PF}_{6}\right](100 \mathrm{mg}, 0.16 \mathrm{mmol})$ suspended in methanol $(10 \mathrm{~mL})$, 2,2'-bipyridine $(25.6 \mathrm{mg}, 0.16 \mathrm{mmol}$ ) was added and the mixture was heated under reflux for $1 \mathrm{~h}$. During this time the colour of the solution changed from yellow to orange and the formation of the product as deep yellow solid was observed. After cooling, the solid was collected by filtration, washed with ethanol and diethyl ether and vacuum dried $(69.4 \mathrm{mg}$, 70\%). Anal. Calc for $\mathrm{C}_{16} \mathrm{H}_{20} \mathrm{ClF}_{6} \mathrm{~N}_{2} \mathrm{PRuS}_{3}$ : C, 31.09; H, 3.26; N, 4.53. Found: C, 30.98; $\mathrm{H}, 3.07 ; \mathrm{N}, 4.38$. The spectral patterns of this compound are coincident with those of the corresponding $\mathrm{CF}_{3} \mathrm{SO}_{3}$ salt [15]. The precursors [Ru([9]aneS $\left.\left.\mathrm{S}_{3}\right)(\mathrm{en}) \mathrm{Cl}\right]\left[\mathrm{PF}_{6}\right]$ and $\left[\mathrm{Ru}\left([9] \mathrm{aneN}_{3}\right)(\mathrm{en})(\mathrm{dmso}-\mathrm{S})\right][\mathrm{Cl}]_{2}(3)$ were prepared as reported elsewhere [16].

\subsubsection{Synthesis and characterization of $\left[R u\left([9] a n e S_{3}\right)(b p y)(p y)\right]\left[P F_{6}\right]_{2}(1)$}

In a light-protected round bottomed flask at ambient temperature $\left[\mathrm{Ru}\left([9] \mathrm{aneS}_{3}\right)(\mathrm{bpy}) \mathrm{Cl}\right]\left[\mathrm{PF}_{6}\right](25.5 \mathrm{mg}, 0.0412 \mathrm{mmol})$ and $\mathrm{AgNO}_{3}(6.8 \mathrm{mg}, 0.0404 \mathrm{mmol})$ were dissolved in a methanol/water $4: 1$ mixture $(10 \mathrm{~mL})$ giving an almost colourless solution. The solution was stirred for ca. $24 \mathrm{~h}$ and precipitation of $\mathrm{AgCl}$ was observed. The solid was removed by centrifugation followed by filtration. A large excess of pyridine $(0.066 \mathrm{~mL}, 0.824 \mathrm{mmol})$ was added to the remaining solution and the reaction mixture stirred again for ca. $18 \mathrm{~h}$. The yellow solution obtained was filtered to eliminate any residual $\mathrm{AgCl}$ or any other particulates and $\mathrm{NH}_{4} \mathrm{PF}_{6}(66.9 \mathrm{mg}, 0.412 \mathrm{mmol})$ and acetone $(1 \mathrm{~mL})$ were added. After two days yellow crystals suitable for X-ray analysis were obtained by slow evaporation of the solvent. The crystals were collected by filtration, washed with methanol and dried in air.

Yield : $23.7 \mathrm{mg}, 71 \%$. Anal. Calc for $\mathrm{C}_{22} \mathrm{H}_{27} \mathrm{~F}_{12} \mathrm{~N}_{3} \mathrm{P}_{2} \mathrm{RuS}_{3}$ : C, 31.27; H, 3.12; N, 5.21. Found C, 31.19; H, 2.75; N, 4.93. UV-Vis $\left(\mathrm{H}_{2} \mathrm{O}\right) / \mathrm{nm}: 240\left(\varepsilon / \mathrm{M}^{-1} \mathrm{~cm}^{-1} 1948\right), 282$ (4018), 398 (596). ${ }^{1} \mathrm{H}-\mathrm{NMR} \delta_{\mathrm{H}}\left(500 \mathrm{MHz} ; \mathrm{D}_{2} \mathrm{O}\right.$, dioxane): 9.22 (d, ${ }^{3} \mathrm{~J} 5.6,2 \mathrm{H}, \mathrm{H} 6,6$ ), 8.65 (d, ${ }^{3} \mathrm{~J}$ 6.7, 2H, H2-py), 8.37 (d, $\left.{ }^{3} \mathrm{~J} 8.2,2 \mathrm{H}, \mathrm{H} 3,3^{\prime}\right), 8.14$ (t, $\left.{ }^{3} \mathrm{~J} 7.9,2 \mathrm{H}, \mathrm{H} 4,4^{\prime}\right), 7.75$ (m, 3H, H4py + H5,5'), 7.25 (t, ${ }^{3} \mathrm{~J}$ 6.3, 2H, H3-py), $3.15\left(\mathrm{~m}, 2 \mathrm{H}, \mathrm{CH}_{2}\left[9 \mathrm{aneS}_{3}\right]\right), 2.88\left(\mathrm{~m}, 2 \mathrm{H}, \mathrm{CH}_{2}\right.$ [9aneS 3 ]), $2.79\left(\mathrm{~m}, 2 \mathrm{H}, \mathrm{CH}_{2}\left[\mathrm{aaneS}_{3}\right]\right), 2.73\left(\mathrm{~m}, 4 \mathrm{H}, \mathrm{CH}_{2}\left[9 \mathrm{aneS}_{3}\right]\right), 2.63\left(\mathrm{~m}, 2 \mathrm{H}, \mathrm{CH}_{2}\right.$ $\left.\left[9 \mathrm{aneS}_{3}\right]\right)$. ESI-MS $m / z: 258.5\left[\mathrm{Ru}\left([9] \mathrm{aneS}_{3}\right)(\mathrm{en})(\mathrm{py})\right]^{2+}$.

\subsubsection{Synthesis and characterization of $\left[R u\left([9] a n e S_{3}\right)(e n)(p y)\right]\left[P F_{6}\right]_{2}(2)$}

In a light-protected round bottomed flask at ambient temperature $\left[\mathrm{Ru}\left([9] \mathrm{aneS}_{3}\right)(\mathrm{en}) \mathrm{Cl}\right]\left[\mathrm{PF}_{6}\right](35.2 \mathrm{mg}, 0.0674 \mathrm{mmol})$ and $\mathrm{AgNO}_{3}(11.2 \mathrm{mg}, 0,0661 \mathrm{mmol})$ were dissolved in a methanol/water $4: 1$ mixture $(10 \mathrm{~mL})$. The yellowish solution was stirred for about $24 \mathrm{~h}$ and afterwards the cloudy mixture was centrifuged. The grey $\mathrm{AgCl}$ precipitate was discarded. Pyridine $(0.109 \mathrm{~mL}, 1.348 \mathrm{mmol})$ was added to the filtrate and the reaction mixture was stirred again for $c a .24 \mathrm{~h}$. The yellow solution obtained was filtered and an excess of $\mathrm{NH}_{4} \mathrm{PF}_{6}(109.4 \mathrm{mg}, 0.674 \mathrm{mmol})$ and acetone $(1 \mathrm{~mL})$ were added. Slow evaporation of the solvent afforded a light yellow solid. Yield : $15.0 \mathrm{mg}$, 31\%. Anal. Calc for $\mathrm{C}_{13} \mathrm{H}_{25} \mathrm{~F}_{12} \mathrm{~N}_{3} \mathrm{P}_{2} \mathrm{RuS}_{3}$ : C, 21.97; H, 3.55; N, 5.91.Found $\mathrm{C}, 21.69 ; \mathrm{H}$, 3.38; N, 5.96. UV-Vis $\left(\mathrm{H}_{2} \mathrm{O}\right) / \mathrm{nm}: 237\left(\varepsilon / \mathrm{M}^{-1} \mathrm{~cm}^{-1} 4615\right), 316$ (4280). ${ }^{1} \mathrm{H}-\mathrm{NMR} \delta(400$ $\mathrm{MHz} ; \mathrm{D}_{2} \mathrm{O}$ ): 8.79 (d, $\left.{ }^{3} \mathrm{~J} 5.29,2 \mathrm{H}, \mathrm{H} 2-\mathrm{py}\right), 7.96$ (t, $\left.{ }^{3} \mathrm{~J} 7.75,1 \mathrm{H}, \mathrm{H} 4-\mathrm{py}\right), 7.53$ (t, ${ }^{3} \mathrm{~J} 6.40,2 \mathrm{H}$, H3-py), 3.79 (br, 2H, $\mathrm{NH}_{\alpha}$ en), 2.83-2.64 (m, 10H, $\mathrm{CH}_{2}$ en and[9aneS 3 ), 2.43 (m, 2H, 
$\mathrm{CH}_{2}$ [9aneS 3$\left.]\right), 2.29\left(\mathrm{~m}, 2 \mathrm{H}, \quad \mathrm{CH}_{2} \quad\left[9 \mathrm{aneS}_{3}\right]\right), 2.22\left(\mathrm{~m}, 2 \mathrm{H}, \quad \mathrm{CH}_{2} \quad\left[9 \mathrm{aneS}_{3}\right]\right)$. Ethylenediamine diasterotopic $\mathrm{NH}_{\beta}{ }^{1} \mathrm{H}$ NMR signals overlap with the residual water peak.

\subsection{X-ray crystallography}

Single crystals of 1 suitable for X-ray analysis were obtained from slow evaporation of the reaction mixture as described above. The data were collected using an Oxford Diffraction Gemini four-circle system with Ruby CCD area detector and the structure was solved by direct methods using SHELXS [17] (TREF) with additional light atoms found by Fourier methods. X-ray crystallographic data for complex $\mathbf{1}$ are available as Supporting Information and have been deposited in the Cambridge Crystallographic Data Centre under the accession numbers CCDC 880474. X-ray crystallographic data in CIF format are available from the Cambridge Crystallographic Data Centre (http://www.ccdc.cam.ac.uk/).

\section{Results and discussion}

\subsection{Synthesis of complexes and molecular structure of $\mathbf{1}$}

Complex $\left[\mathrm{Ru}\left([9] \mathrm{aneS}_{3}\right)(\mathrm{bpy})(\mathrm{py})\right]\left[\mathrm{PF}_{6}\right]_{2}(\mathbf{1})$ was prepared in a similar manner as reported for $\left[\left(\eta^{6} \text {-arene }\right) \operatorname{Ru}(N, N)(\mathrm{L})\right]^{2+}$ compounds $[5]$ : the parent chloride complex[Ru([9]aneS 3$)\left(\right.$ bpy)Cl] $\left[\mathrm{PF}_{6}\right]$ reacted with $\mathrm{AgNO}_{3}$ to afford the aqua adduct $\left[\mathrm{Ru}\left([9] \mathrm{ane} \mathrm{S}_{3}\right)(\mathrm{bpy})\left(\mathrm{H}_{2} \mathrm{O}\right)\right]^{2+}$ which was then treated with an excess of pyridine to give $\mathbf{1}$ after precipitation with $\mathrm{NH}_{4} \mathrm{PF}_{6}$.

The same procedure was adopted for complex $\mathbf{2}$, while $\mathbf{3}$ was prepared as described elsewhere [Error! Bookmark not defined.]. All complexes were fully characterized by ${ }^{1} \mathrm{H}-\mathrm{NMR}$ spectroscopy, mass spectrometry and elemental analysis. Moreover, the molecular structure of $\mathbf{1}$ was determined by X-ray crystallography. A perspective view of the cation is given in Fig. 1, while selected bond distances and angles are reported in Table 1 and compared with the DFT-optimized structural parameters. 


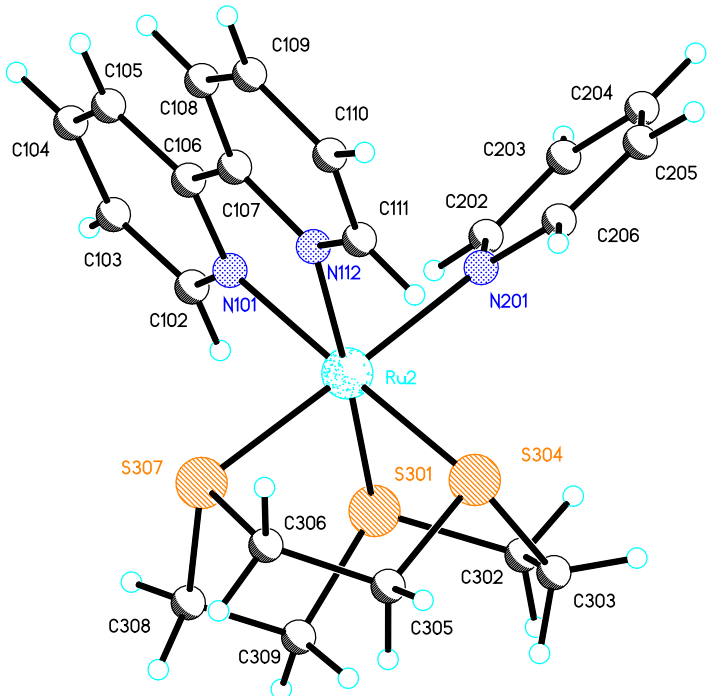

Fig. 1. Solid state structure of the cation of complex $\left[\mathrm{Ru}\left([9] \mathrm{aneS}_{3}\right)(\mathrm{bpy})(\mathrm{py})\right]\left[\mathrm{PF}_{6}\right]_{2}(\mathbf{1})$ with atom numbering scheme. Thermal ellipsoids show $50 \%$ probability.

Complex 1 displays a Ru-N(py) distance of 2.1295(12) A, slightly longer than the Ru$\mathrm{N}$ (bpy) distances of $2.090 \AA$ (see Table 1). The sulfur atoms of the [9] aneS 3 ligand are at 2.302-2.315 $\AA$ from the ruthenium centre and binding angles of the ligand approach $90^{\circ}$. Only the S301-Ru2-S304 angle is significantly smaller $\left(85.391^{\circ}\right)$, causing a distortion in the [9] ane $S_{3}$ ligand structure. DFT-optimized ground state geometry is in very good agreement with the X-ray data. Bond distances are overestimated by less than $0.06 \AA$. The lowest-lying triplet geometry was calculated as well, by virtue of the key role that such state plays in the photochemistry of transition metal complexes [18]. It is observed that in the triplet state all the $\mathrm{Ru}-\mathrm{N}$ bonds are slightly contracted while the $\mathrm{Ru}-\mathrm{S}$ bonds are elongated by ca. $0.1 \AA$ compared to the ground state structure. Crystallographic details and crystal packing information for complex $\mathbf{1}$ are reported in the Supporting Information (Table 1 and Figure S1).

\section{Table 1}

Selected X-ray bond lengths $(\AA)$ and angles $\left(^{\circ}\right)$ for $\mathbf{1}$ together with calculated (DFT) values.

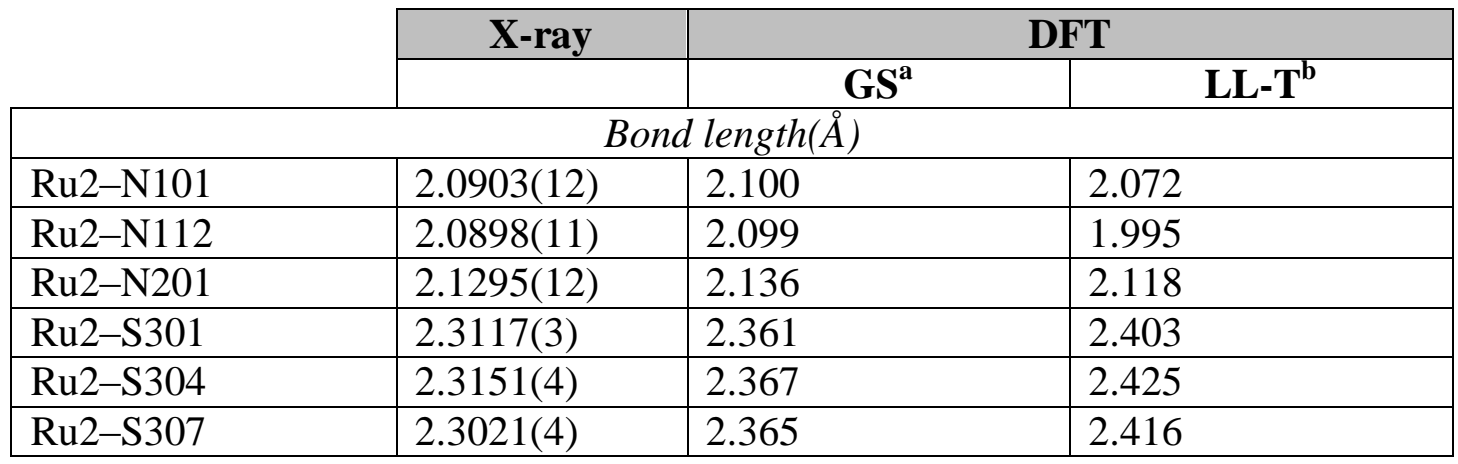




\begin{tabular}{|l|l|l|l|}
\hline \multicolumn{5}{|c|}{ Bond angles $\left(^{\circ}\right)$} \\
\hline N101-Ru2-N112 & $78.25(5)$ & 77.996 & 80.817 \\
\hline N101-Ru2-N201 & $88.83(5)$ & 89.430 & 89.637 \\
\hline N112-Ru2-N201 & $87.92(5)$ & 88.370 & 91.898 \\
\hline S301-Ru2-S304 & $85.392(12)$ & 86.485 & 85.551 \\
\hline S301-Ru2-S307 & $88.845(13)$ & 87.678 & 87.476 \\
\hline S304-Ru2-S307 & $88.449(13)$ & 87.316 & 86.063 \\
\hline
\end{tabular}

${ }^{\mathrm{a}} \mathrm{GS}=$ Ground state geometry

${ }^{\mathrm{b}}$ LL-T $=$ Lowest lying triplet geometry

\subsection{Dark stability and photochemical behavior of 1-3 in aqueous solution}

Complex 1 is very stable in aqueous solution in the dark. Indeed, no changes were observed in the UV-Vis and ${ }^{1} \mathrm{H}-\mathrm{NMR}$ spectra of $\mathbf{1}$ even after six days at $298 \mathrm{~K}$ or overnight at $310 \mathrm{~K}$. However upon light irradiation $\left(\lambda_{\mathrm{ex}}=420 \mathrm{~nm}\right)$ of $\mathbf{1}$ in $\mathrm{H}_{2} \mathrm{O}$, rapid changes occurred in the UV-Vis spectrum. Three isosbestic points were observed when the photoreaction was monitored by UV-Vis spectroscopy (Fig. 2A). The band at $282 \mathrm{~nm}$ decreased in intensity while the bands at 240 and $398 \mathrm{~nm}$ were slightly red-shifted. After ca. 10 min of irradiation no further significant changes were observed at the irradiation power $\left(7 \mathrm{~mW} / \mathrm{cm}^{2}\right)$ and complex concentration $(100 \mu \mathrm{M})$ used. These changes correspond to the release of the coordinated pyridine and formation of the aqua adduct (Scheme 1). Light activation was also achieved using $467 \mathrm{~nm}$ light, while excitation at $517 \mathrm{~nm}$ did not induce formation of photoproducts.
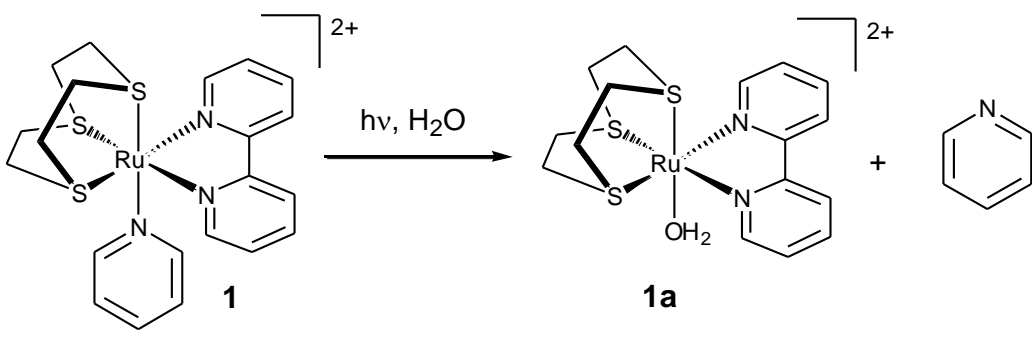

$1 a$

Scheme 1.

Analogously, complex $\left[\mathrm{Ru}\left([9] \mathrm{aneS}_{3}\right)(\mathrm{en})(\mathrm{py})\right]\left[\mathrm{PF}_{6}\right]_{2}(\mathbf{2})$ was stable in aqueous solution (up to six days), but readily reacted upon irradiation. Light excitation caused a decrease in the intensity of the two main bands of its UV-Vis spectrum (237 and 316 $\mathrm{nm}$ ), and the appearance of new bands at 247 and $375 \mathrm{~nm}$. Three isosbestic points were observed at 246, 266 and $377 \mathrm{~nm}$, suggesting that the photoreaction produces a single product. After 40 min of irradiation there was no further change in the spectrum (Figure S2).

Complex $\left[\mathrm{Ru}\left([9] \mathrm{aneN}_{3}\right)(\mathrm{en})(\mathrm{dmso}-\mathrm{S})\right][\mathrm{Cl}]_{2}(3)$ also appeared to be stable in the dark (overnight at $310 \mathrm{~K}$ ), however its photoactivity was lower. In the UV-Vis spectrum of 3 , the band at $214 \mathrm{~nm}$ decreased in intensity while the band at $306 \mathrm{~nm}$ was red shifted and more intense. Similarly to $\mathbf{1}$ and $\mathbf{2}$, an isosbestic point is present at $254 \mathrm{~nm}$ (Figure S3), confirming the formation of a single photoproduct. 
The photoreactions of complexes $\mathbf{1}-\mathbf{3}$ were also followed by ${ }^{1} \mathrm{H}-\mathrm{NMR}$ spectroscopy in $\mathrm{D}_{2} \mathrm{O}$. After $20 \mathrm{~min}$ of irradiation at $420 \mathrm{~nm}$ (Fig. 2B), complex 1 completely released the pyridine ligand forming the aqua adduct $\left[\mathrm{Ru}\left([9] \mathrm{aneS}_{3}\right)(\mathrm{bpy})\left(\mathrm{H}_{2} \mathrm{O}\right)\right]^{2+}(\mathbf{1 a})$, as clearly indicated by the chemical shift of the bpy resonances [15] and by the appearance of free pyridine peaks in the ${ }^{1} \mathrm{H}$ spectrum. These results are in agreement with the reported observations for analogue piano-stool ruthenium complexes [5]. ESI-MS further confirmed the nature of the photoproduct giving the expected peak for the aqua complex at $\mathrm{m} / \mathrm{z} 227.9962$ (predicted $227.9964 \mathrm{~m} / \mathrm{z}$ ) with the expected isotopic pattern. ${ }^{1} \mathrm{H}-\mathrm{NMR}$ shows that in the photolyzed solution the reverse binding of pyridine to $\mathbf{1 a}$ is very slow and not quantitative (see below).

Similar behaviour was observed when photolysis experiments were performed in PBS buffer. However, a new minor species (ca. 7\%) (bpy resonances at 9.14 (d), 8.41 (d), 8.09 (t) 7.59 (t)) also formed in PBS buffer under prolonged light irradiation (150 min), probably due to the formation of the phosphate adduct, since comparison with the ${ }^{1} \mathrm{H}$ NMR spectrum of complex 1 rules out the formation of the chlorido derivative (Fig. S4).

(A)

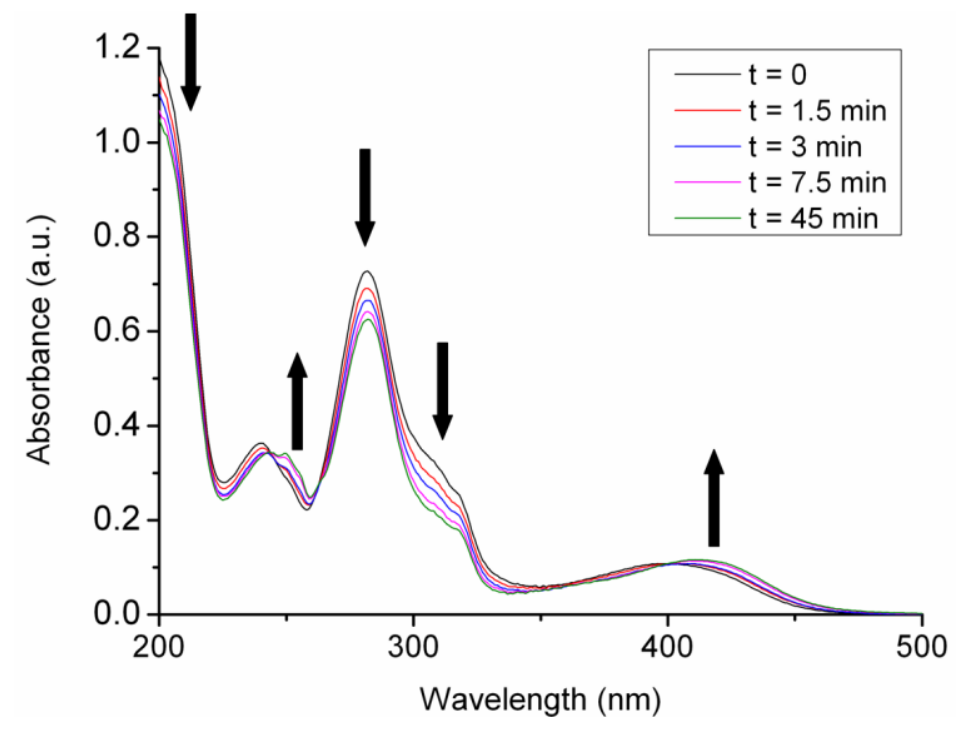

(B) 


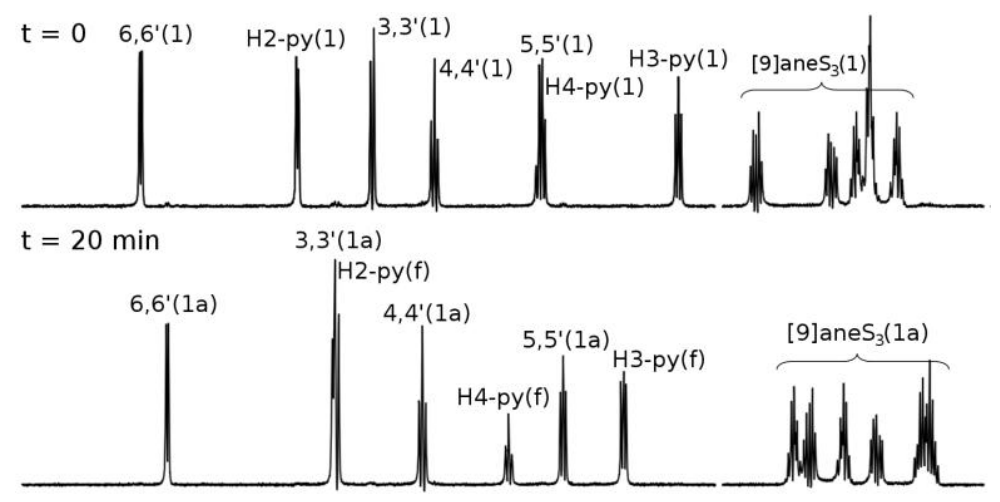

$\begin{array}{llllllllllllllllll}9.6 & 9.4 & 9.2 & 9.0 & 8.8 & 8.6 & 8.4 & \begin{array}{l}8.2 \\ \text { chemical shift }(\mathrm{ppm})\end{array} & 7.4 & 7.2 & 3.2 & 3.0 & 2.8 & 2.6 & 2.4\end{array}$

Fig. 2. (A) UV-Vis spectra of $\left[\mathrm{Ru}\left([9] \mathrm{ane}_{3}\right)(\mathrm{bpy})(\mathrm{py})\right]\left[\mathrm{PF}_{6}\right]_{2}$ (1) in aqueous solution recorded at different irradiation times $\left(\lambda_{\mathrm{ex}}=420 \mathrm{~nm}, 7 \mathrm{~mW} / \mathrm{cm}^{2}\right)$; (B) ${ }^{1} \mathrm{H}-\mathrm{NMR}$ spectra of 1 in $\mathrm{D}_{2} \mathrm{O}$ at $\mathrm{t}=0 \mathrm{~min}$ and after $20 \mathrm{~min}$ of irradiation $\left(\lambda_{\mathrm{ex}}=420 \mathrm{~nm}, 20 \mathrm{~mW} / \mathrm{cm}^{2}\right)$; 1 a is the aqua species $\left[\mathrm{Ru}\left([9] \mathrm{aneS}_{3}\right)(\mathrm{bpy})\left(\mathrm{H}_{2} \mathrm{O}\right)\right]^{2+}$, py(f) indicates free pyridine.

${ }^{1} \mathrm{H}$-NMR monitoring of the photolysis of complex 2 gave comparable results (Figure S5). Upon light-induced formation of the aqua complex $\left[\mathrm{Ru}\left([9] \mathrm{aneS}_{3}\right)(\mathrm{en})\left(\mathrm{H}_{2} \mathrm{O}\right)\right]^{2+}(\mathbf{2 a})$ the signals of the diastereotopic $\mathrm{NH}$ 1,2-diaminoethane protons became observable as they were no longer overlapped by the solvent and reference signals. The formation of the aqua species 2a was also confirmed by comparison with the spectrum of the labile $\left[\mathrm{Ru}\left([9] \mathrm{aneS}_{3}\right)(\mathrm{en}) \mathrm{Cl}\right]\left[\mathrm{PF}_{6}\right]$, which gave the same aqua species 2a upon release of the $\mathrm{Cl}$ ligand $[15,16]$. Interestingly, resonances for coordinated py in 2 could still be seen after $60 \mathrm{~min}$ of irradiation, indicating that the photo-induced ligand release was not complete (92\% from NMR signal integration).

In the case of $3,{ }^{1} \mathrm{H}$-NMR spectra recorded at different times of irradiation showed the release of the dmso ligand (Figure S6). A singlet at $\delta=2.72$ corresponding to free dmso progressively increased in intensity, while the peak of the coordinated dmso-S at $\delta$ $=3.33$ decreased in intensity, indicating the formation of $\left[\mathrm{Ru}\left([9] \mathrm{aneN} \mathrm{N}_{3}\right)(\mathrm{en})\left(\mathrm{H}_{2} \mathrm{O}\right)\right]^{2+}(\mathbf{3 a})$. The concentration of free dmso increased during the first two hours of irradiation, eventually reaching a plateau corresponding to the formation of ca. $23 \% \mathbf{3 a}$.

\subsection{Irradiation of $\mathbf{1}-\mathbf{3}$ in the presence of model biomolecules}

To study the ability of 1 to bind to DNA bases, photolysis $\left(\lambda_{\mathrm{ex}}=420 \mathrm{~nm}\right)$ of a PBS solution ( $\mathrm{pH}$ 7.2) containing the complex and 9-ethylguanine (9-EtG) in a 1:1 mol ratio was monitored by ${ }^{1} \mathrm{H}-\mathrm{NMR}$ spectroscopy. In the dark at $310 \mathrm{~K}$ no dissociation of pyridine and consequently no interaction with 9-EtG was observed. In contrast, light excitation in the presence of 9-EtG resulted in the release of the py ligand and formation of the aqua complex 1a, which readily reacted with 9-EtG to give the $\left[\mathrm{Ru}\left([9] \mathrm{aneS}_{3}\right)(\mathrm{bpy})(9-\mathrm{EtG})\right]^{2+}$ adduct (1-G). The progress of the reaction is shown in Fig. 3 , where the formation of $\mathbf{1 - G}$ is demonstrated by the appearance of a singlet at about 
$8.00 \mathrm{ppm}$, corresponding to the $\mathrm{H} 8$ proton of the coordinated 9-EtG. The resonances of coordinated bpy in 1-G are slightly shifted compared to both $\mathbf{1}$ and $\mathbf{1 a}$, and the relative integration of the new bpy and 9-EtG signals is consistent with the formation of 1-G. A ${ }^{1} \mathrm{H}-{ }^{1} \mathrm{H}$ NOESY experiment, performed after $20 \mathrm{~min}$ of irradiation, showed a clear correlation peak between the H8 singlet of bound 9-EtG and the H6,6' doublet of bpy, confirming the formation of the nucleobase adduct 1-G (Fig. S7). After six further hours in the dark, the reaction reached equilibrium, and compound 1-G was the most abundant (50\%) compared to $\mathbf{1}(15 \%)$ and its aqua derivative $\mathbf{1 a}(35 \%)$.

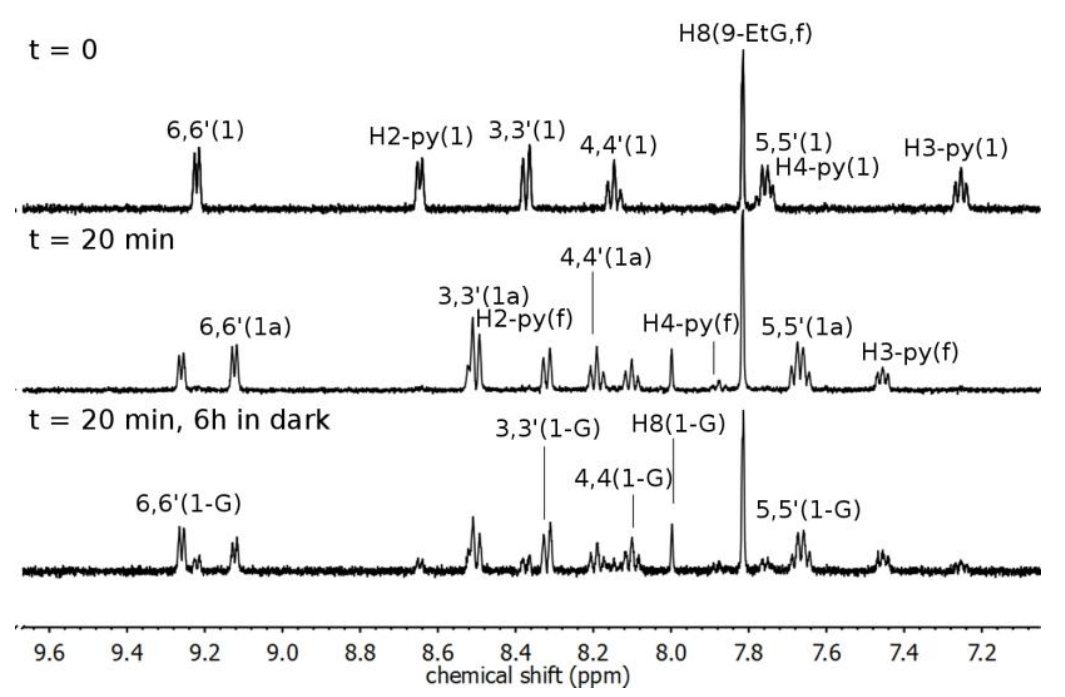

Fig. 3. Aromatic region of the ${ }^{1} \mathrm{H}-\mathrm{NMR}$ spectrum of $\left[\mathrm{Ru}\left([9] \mathrm{aneS}_{3}\right)(\mathrm{bpy})(\mathrm{py})\right]\left[\mathrm{PF}_{6}\right]_{2}(\mathbf{1})$ and 9-EtG in $\mathrm{D}_{2} \mathrm{O}$ (1:1 mixture, PBS buffer, $\mathrm{pH}$ 7.2) recorded after various irradiation times $\left(\lambda_{\mathrm{ex}}=420 \mathrm{~nm}, 20 \mathrm{~mW} / \mathrm{cm}^{2}\right)$; py(f) indicates free pyridine and $\mathrm{H} 8(\mathbf{1 - G})$ is the resonance of the $\mathrm{H} 8$ proton of the coordinated $9-\mathrm{EtG}$ in $\left[\mathrm{Ru}\left([9] \mathrm{aneS}_{3}\right)(\mathrm{bpy})(9-\mathrm{EtG})\right]^{2+}$.

A similar procedure was employed for complexes $\mathbf{2}$ and $\mathbf{3}$, although in unbuffered $\mathrm{D}_{2} \mathrm{O}$. In the presence of 9-EtG both complexes were stable in the dark at $37{ }^{\circ} \mathrm{C}$ (overnight), and underwent photoreaction to give the corresponding aqua derivatives and subsequent coordination of the nucleobase. New $\mathrm{H} 8$ peaks of the $\mathbf{2 - G}$ and $\mathbf{3 - G}$ adducts were observed at lower fields ( 0.5 and $0.2 \mathrm{ppm}$ respectively) in the ${ }^{1} \mathrm{H}$ NMR spectra of the irradiated samples (Figure S8 and S9). After 180 min under light excitation (when 100\% py dissociation had occurred), 2-G accounted for $c a$. $56 \%$ of the total complex in solution, while with 135 min of irradiation and incubation at $37{ }^{\circ} \mathrm{C}$ overnight only a small fraction of 3-G (ca. 7\%) was formed.

Given the relevance of glutathione ( $\gamma$-L-Glu-L-Cys-Gly, GSH) - the abundant intracellular tripeptide - as metal detoxification agent [19], its interaction with 1 was studied by ${ }^{1} \mathrm{H}-\mathrm{NMR}$ spectroscopy (PBS, $\mathrm{pH}$ 7.2) both in the dark and under light irradiation (Fig. 4). When left in the dark overnight no reaction was observed between 1 and GSH (1:1 mol ratio). On the contrary, light excitation clearly caused the formation of Ru-GSH adducts. In the aromatic region of the ${ }^{1} \mathrm{H}-\mathrm{NMR}$ spectrum a new set of signals for coordinated bpy appeared, in addition to those expected for 1a. The new resonances 
were tentatively attributed to the adduct $\left[\mathrm{Ru}\left([9] \mathrm{aneS}_{3}\right)(\mathrm{bpy})(\mathrm{GS})\right]^{2+}(\mathbf{1 - G S})$, in which GSH is presumably bound through the deprotonated $\mathrm{S}$ atom. In the aliphatic part of the spectrum new signals were observed for GSH and [9] $\mathrm{aneS}_{3}$, but a full assignment was not possible due to the presence of extensive overlap. Nevertheless, a new signal (dd) at 3.60 ppm was tentatively assigned to one of the $\mathrm{CH}_{2}$ protons adjacent to the $\mathrm{S}$ atom of GSH that are diastereotopic. The signals of 1-GS increased with time until they reached a plateau after $140 \mathrm{~min}$ of irradiation. At that point the composition of the solution was (according to bpy integration) ca. 43\% 1-GS and 57\% $\mathbf{1 a .}$

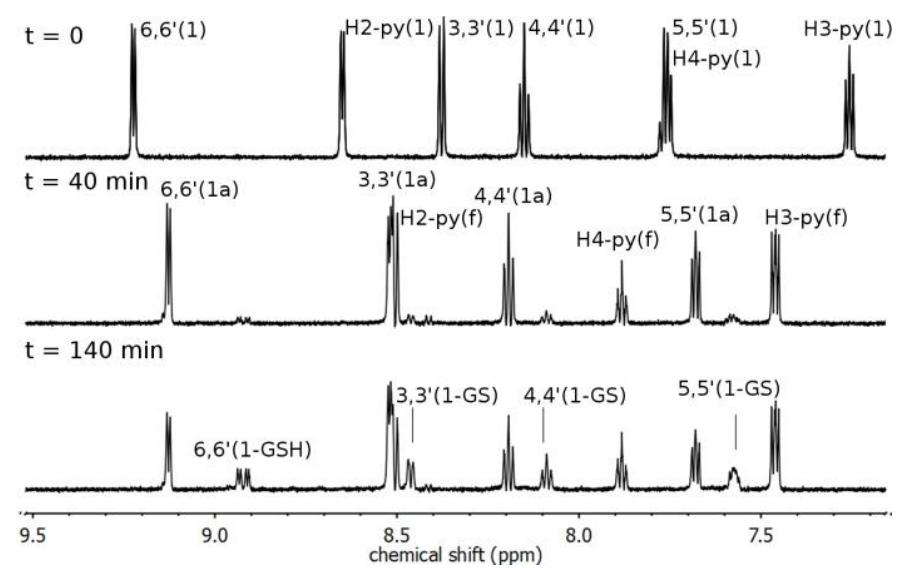

Fig. 4. Aromatic region of the ${ }^{1} \mathrm{H}-\mathrm{NMR}$ spectrum of $\mathbf{1}$ and GSH in PBS (1:1 mixture, $\mathrm{pH}$ 7.2) recorded at different irradiation times; py(f) indicates free pyridine, 1-GS indicates $\left[\mathrm{Ru}\left([9] \mathrm{aneS}_{3}\right)(\mathrm{bpy})(\mathrm{GS})\right]^{2+}$.

\subsection{Oligonucleotide binding of $\mathbf{1}$ under light irradiation}

The interaction of 1 with the single strand oligonucleotide d(ATACATGCTACATA) (1:1 mol ratio, $250 \mu \mathrm{M})$ under irradiation with visible light was investigated by HPLC and mass spectrometry. After just 30 min of irradiation $\left(\lambda_{\mathrm{ex}}=420 \mathrm{~nm}\right)$ complex $1 \mathbf{a}$ was found to bind significantly to the oligonucleotide. The integration of the total peak area of the chromatograms indicated that the extent of binding by 1a to the oligonucleotide was ca. $50 \%$ after $30 \mathrm{~min}$ of light exposure (Figure S10), increasing to $65 \%( \pm 3 \%)$ after $90 \mathrm{~min}$. MS analysis of the irradiated solution detected the presence of the unreacted oligonucleotide, the oligonucleotide with one $\left\{\operatorname{Ru}\left([9] \text { ane } S_{3}\right)(\text { bpy })\right\}^{2+}$ fragment bound (Figure S11, predicted $1554.2438 \mathrm{~m} / z$, observed $1554.2254 \mathrm{~m} / \mathrm{z}$ ), and a very small amount of the oligonucleotide bearing two $\left\{\mathrm{Ru}\left([9] \mathrm{aneS}_{3}\right)(\mathrm{bpy})\right\}^{2+}$ fragments (predicted $1699.8950 \mathrm{~m} / \mathrm{z}$, observed $1699.8774 \mathrm{~m} / \mathrm{z}$ ). All species were detected in the $3^{-}$charge state. As demonstrated by the 9-EtG binding experiment, it is likely that $\mathbf{1 a}$ binds first at the single guanine residue, as the N7 of guanine is usually the preferred DNA site for transition metal ions [20]. A minor adenine adduct may also be present, giving rise to the species observed at $1699.8774 \mathrm{~m} / \mathrm{z}$ that however eluded HPLC detection. 
3.5. Molecular orbitals and spin surface analysis for complex 1 in the singlet ground state and in the lowest-lying triplet state geometry.

Complex 1 was selected for a more detailed computational study aimed at characterizing its electronic properties. The electronic structure of $\mathbf{1}$ was calculated in solution $\left(\mathrm{H}_{2} \mathrm{O}\right)$ for both the singlet ground state and the lowest-lying triplet state geometries using the CPCM method [10]. Selected molecular orbitals and the spin density surface for the triplet geometry are described in Fig. 5. In the ground state configuration, the frontier occupied orbitals - HOMO, HOMO-1, and HOMO-2 - have all a marked metal-centered character, although contributions from pyridine, bpy, and [9]aneS ${ }_{3}$ ligands are present. The four lowest unoccupied orbitals are all prevalently bpy-based while the LUMO+4 and LUMO+5 have a significant metal contribution. Moreover, these two latter orbitals have a strong $\sigma$-antibonding character towards the bpy and pyridine ligands. Such orbitals are likely to play a role in the photochemistry of complex $\mathbf{1}$ [21].

In the lowest-lying triplet geometry, the unpaired electrons are localized on two bpy-based SOMOs (singly occupied molecular orbitals). The lowest-SOMO (1-SOMO) has also a noteworthy ruthenium contribution. This can also be appreciated in the spin density surface where the Ru-bpy character is particularly evident and it is in agreement with the TDDFT results on the lowest energy triplet excited state (vide infra). 

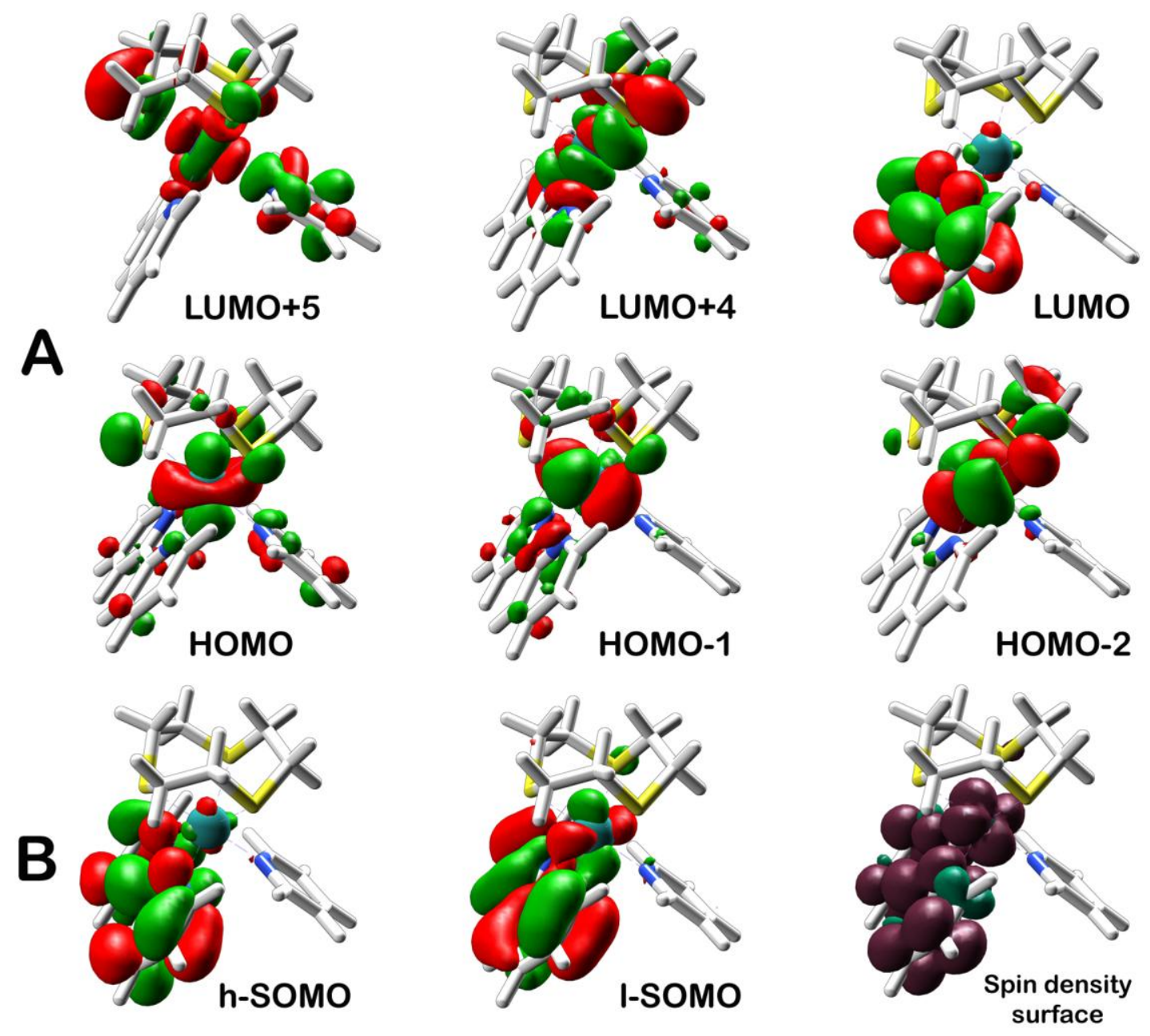

Fig. 5. (A) Selected molecular orbitals for 1 in the singlet ground state;(B) SOMOs and spin density surfacefor $\mathbf{1}$ in the lowest lying triplet state.

\subsection{Absorption properties of complex 1.}

As discussed in Section 3.2, the absorption spectrum of 1 shows three major bands and a shoulder (Figure 6). Singlet transitions were calculated employing TDDFT to assign the character of the bands in the UV-Vis spectrum. All the details on the calculated transitions are reported in the Supporting Information (Table S2).

Despite a blue shift of ca. 20-25 nm, calculations predict well the shape of the spectrum. In the experimental spectrum, the lowest-energy band is centered at $399 \mathrm{~nm}(\varepsilon$ $=3286 \mathrm{M}^{-1} \mathrm{~cm}^{-1}$ ) and has a MLCT character as shown by the electron density difference map (EDDM) S1. At higher energies the most intense peak $\left(\varepsilon=19672 \mathrm{M}^{-1} \mathrm{~cm}^{-1}\right)$ and the shoulder fall at 281 and $309 \mathrm{~nm}$, respectively. The corresponding EDDMs highlight a $\mathrm{Ru} \rightarrow$ bpy MLCT (S13 and S17) character also for this band, although the py is partially involved as well. The third peak is at $239 \mathrm{~nm}\left(\varepsilon=10658 \mathrm{M}^{-1} \mathrm{~cm}^{-1}\right)$ and has major intraligand character (S36: py $\rightarrow$ bpy). Interestingly, there are weak transitions in the 350 
$\mathrm{nm}$ region (calculated) that have a dissociative $\mathrm{MC}$ character because of significant contributions from the $\sigma$-antibonding orbitals LUMO+4 and LUMO+5 (e. g. S4, Table S1).

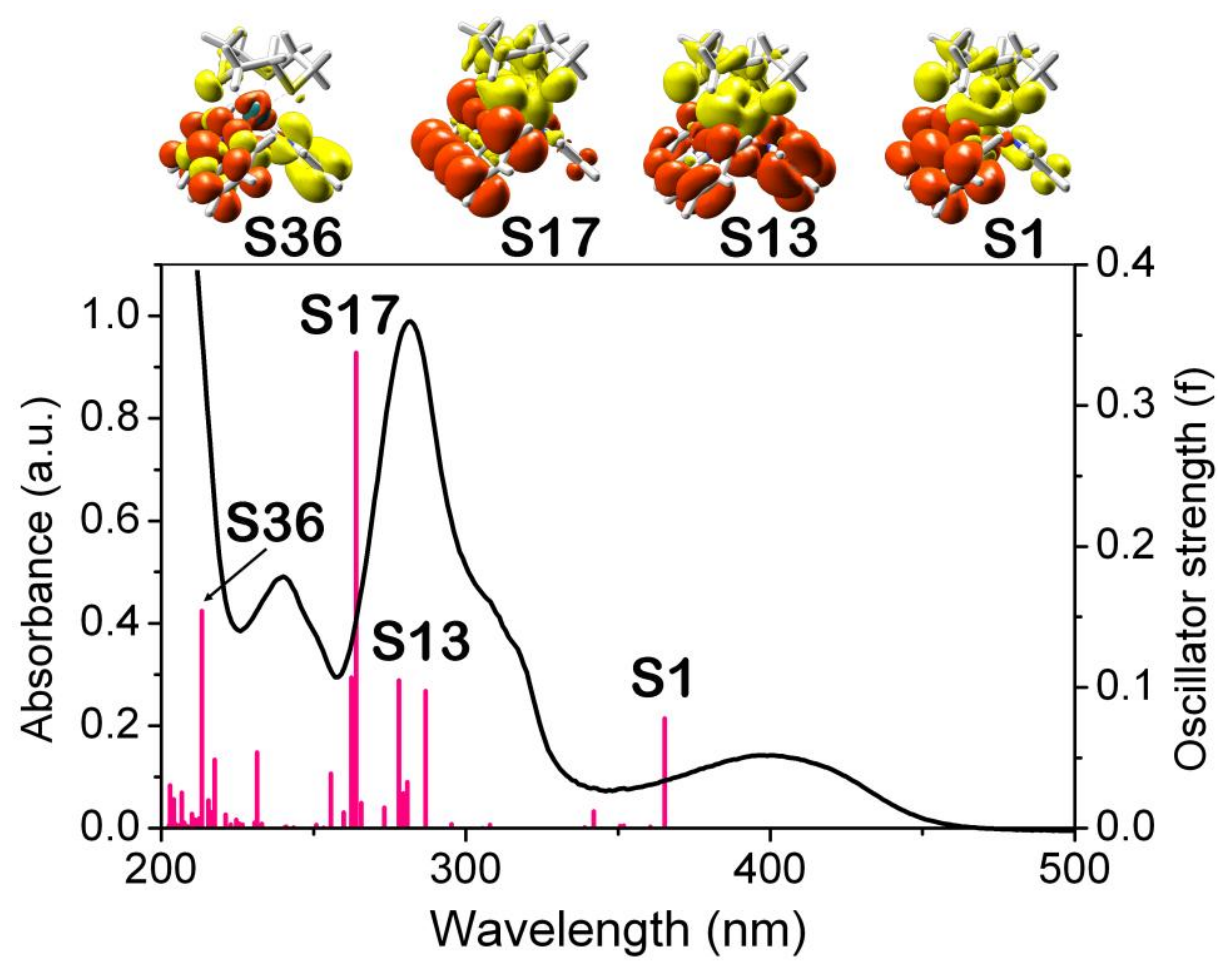

Fig. 6. Experimental absorption spectrum (black line) and calculated singlet excited state transitions (magenta vertical bars) of $\mathbf{1}$ in $\mathrm{H}_{2} \mathrm{O}$. The vertical bar height is the oscillator strength. Selected Electron Density Difference Maps (EDDMs) of singlet excited state transitions of $\mathbf{1}$ are reported on the top of the box. Yellow indicates a decrease in electron density, while orange indicates an increase.

\subsection{Triplet excited states and general remarks on the photochemistry of 1.}

Dissociative singlet excited states (e. g. S4, Table S1) may be responsible for pyridine release from 1 upon light excitation. However, triplet states are generally involved in the photochemistry of ruthenium complexes since they become efficiently populated after intersystem crossing (ISC). For such reason we have investigated the nature of the lowest-energy triplet states by TDDFT (Figure 7). Consistent with the UKS (unrestricted Kohn-Sham) calculations, the lowest-lying triplet has a ${ }^{3}$ MLCT character (T1). Similar character is observed for a state lying at higher energy (T2, $0.4 \mathrm{eV})$, while two highly dissociative ${ }^{3} \mathrm{MC}$ states (T3 and T4) are at $0.73-0.83 \mathrm{eV}$ from $\mathrm{T} 1$. These ${ }^{3} \mathrm{MC}$ states have dominant contributions from orbitals such as the LUMO+5 represented in Fig. 5A. Moreover, according to the calculations, they have lower energy than the lowest singlet S1 and could therefore be easily populated by ISC and then promote the release of the py ligand [22]. This scenario is in agreement with the lack of luminescence in solution of $\mathbf{1}$ and with its high reactivity. 

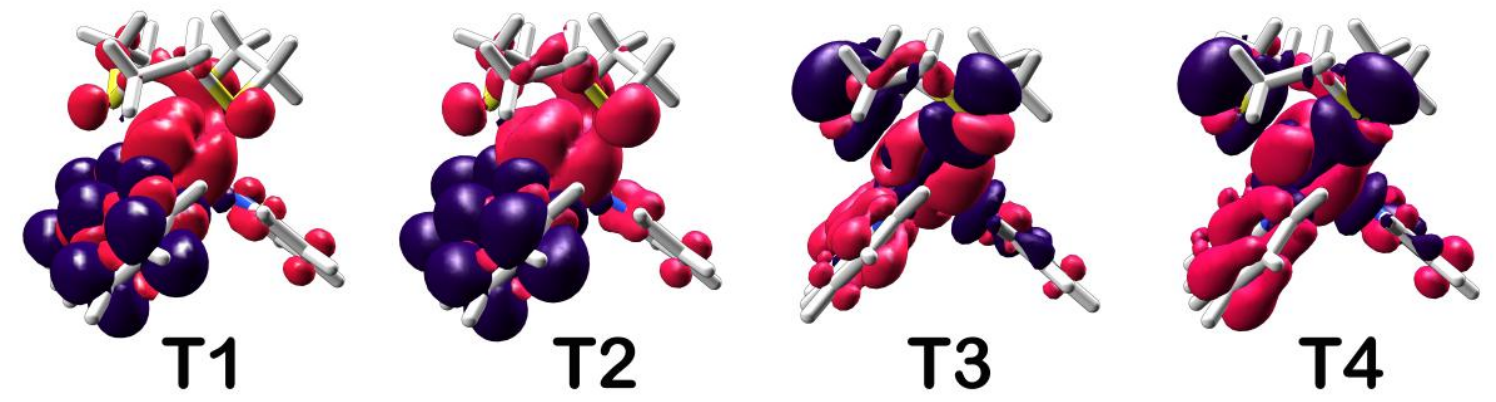

Fig. 7. Selected Electron Density Difference Maps (EDDMs) of the four lowest energy triplet excited states of $\mathbf{1}$. Magenta indicates a decrease in electron density, while purple indicates an increase.

\section{Conclusions}

The aim of this work was to study the photochemistry of some Ru(II) half-sandwich coordination compounds, structurally similar to the inert organometallic compounds of general formula $\left[\left(\eta^{6} \text {-arene }\right) \mathrm{Ru}(N, N)(\mathrm{L})\right]^{2+}$ developed in recent years by Sadler and coworkers, that can be activated by photo-induced dissociation of the monodentate ligand upon irradiation with visible light. Thus two new [9] aneS $\mathrm{S}_{3}$ complexes, $\left[\mathrm{Ru}\left([9] \mathrm{aneS}_{3}\right)(\mathrm{bpy})(\mathrm{py})\right]\left[\mathrm{PF}_{6}\right]_{2}(\mathbf{1})$ and $\left[\mathrm{Ru}\left([9] \mathrm{aneS}_{3}\right)(\mathrm{en})(\mathrm{py})\right]\left[\mathrm{PF}_{6}\right]_{2}(\mathbf{2})$, were prepared

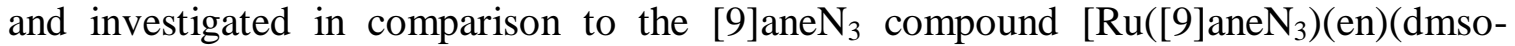
$\mathrm{S})][\mathrm{Cl}]_{2}(3)$. They were found to be completely inert in solution in the absence of light, which is a desirable pre-requisite for photoactivatable pro-drugs.

The photochemical studies showed that the three half-sandwich $\mathrm{Ru}(\mathrm{II})$ complexes $\mathbf{1}-\mathbf{3}$ dissociate to some extent the monodentate ligand upon irradiation with visible light $\left(\lambda_{\mathrm{ex}}=\right.$ $420 \mathrm{~nm}$ ) of moderate power (ca. $20 \mathrm{~mW} / \mathrm{cm}^{2}$ ) and give selectively the corresponding aqua species. When the photoactivation is performed in the presence of an equimolar amount of the model DNA base 9-EtG, coordination through N7 occurs. Data summarizing the results for the three complexes are given in Table 2.

Table 2. Extent $(\%)$ of light-induced $\left(\lambda_{\mathrm{ex}}=420 \mathrm{~nm}, 20 \mathrm{~mW} / \mathrm{cm}^{2}\right)$ aquation and 9-EtG binding for complexes $\mathbf{1}-\mathbf{3}$.

\begin{tabular}{llll}
\hline Complex & Irr. time (min) & \% of aqua species & \% binding to 9-EtG \\
\hline $\mathbf{1}$ & 2 & 100 & 50 \\
$\mathbf{2}$ & 40 & 92 & 56 \\
$\mathbf{3}$ & 360 & 23 & 7 \\
\hline
\end{tabular}

These data clearly show that both the nature of the face-capping ligand and of the leaving group have a remarkable influence on the photoactivation process: whereas both the [9] ane $S_{3}$ complexes $\mathbf{1}$ and $\mathbf{2}$ have excellent photoactivation parameters (rate and extent of 
pyridine dissociation, extent of reaction with 9-EtG) that compare very well with most of the organometallic analogues investigated so far, the strong $\mathrm{Ru}-\mathrm{S}$ (dmso) bond in the [9] ane $\mathrm{N}_{3}$ complex 3 is not easily broken even by the action of light and the extent of photoactivation is modest. Also the nature of the chelating ligand has a strong impact on the photoactivation rate ( $c f$. 1 with 2 ), possibly because there is a marked increase in the absorbance at the irradiation wavelength when the bpy aromatic system replaces 1,2diaminoethane. Nevertheless, complex $\left[\mathrm{Ru}\left([9] \mathrm{aneS}_{3}\right)(\mathrm{py})_{3}\right]\left[\mathrm{PF}_{6}\right]_{2}$, that was extensively investigated by Thomas and co-workers for synthetic purposes and is structurally very similar to $\mathbf{1}$, has been described as photo-inactive [23]. In the case of $\mathbf{1}$, DFT calculations show that, dissociative ${ }^{3} \mathrm{MC}(\mathrm{d}-\mathrm{d}$ ligand field) states are accessible and can promote specific photodissociation of the pyridine ligand.

These interesting properties of $\mathbf{1}$ prompted us to extend our studies on this compound. We found that upon photoactivation the complex is capable of binding efficiently, not only to 9-EtG, but also to the single strand oligonucleotide $\mathrm{d}$ (ATACATGCTACATA) and to glutathione. Moreover, photoactivation occurs also with the less energetic light at $463 \mathrm{~nm}$.

In the future we plan to perform in vitro antiproliferative tests on compounds 1 and $\mathbf{2}$, and their analogues, both in the dark and upon photo-irradiation, in order to assess if the photoactivation and reactivity observed in the test-tube leads to cytotoxicity towards cancer cells. The in vitro results will be compared with those previously obtained for the chlorido compounds $\left[\mathrm{Ru}\left([9] \mathrm{aneS}_{3}\right)(\mathrm{bpy}) \mathrm{Cl}\right]\left[\mathrm{PF}_{6}\right]$ and $\left[\mathrm{Ru}\left([9] \mathrm{aneS} \mathrm{S}_{3}\right)(\mathrm{en}) \mathrm{Cl}\right]\left[\mathrm{PF}_{6}\right]$ that in aqueous solution undergo substitution of the $\mathrm{Cl}$ ligand and generate the same aqua species as complexes $\mathbf{1}$ and $\mathbf{2}, \mathbf{1 a}$ and $\mathbf{2 a}$, respectively.

\section{Acknowledgements}

G.R. thanks COST action D39 "Metallo-Drug design and action" for funding. L.S. was supported by ERC BIOINCMED (grant no. 247450 to P.J.S.). E.A. thanks Fondazione Beneficentia Stiftung for financial support and BASF Italia Srl for a generous donation of hydrated ruthenium chloride.

\section{Appendix A. Supplementary material}

X-ray crystallographic data for complex 1 (deposited in the Cambridge Crystallographic Data Centre under the accession numbers CCDC 880474), UV-Vis and NMR (1D and 2D) spectra for complexes 1-3 under different irradiation conditions, oligonucleotidebinding HPLC and mass spectrometry data for complex 1, TDDFT excited-state transitions for complex 1. Supplementary data associated with this article can be found, in the online version, at doi:XXX. 


\section{Graphical Abstract}

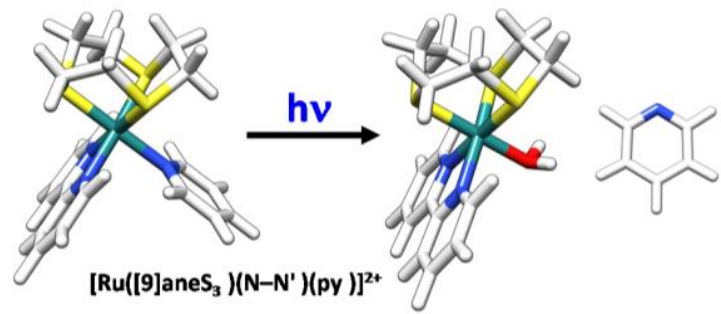




\section{References}

[1] N. J. Farrer, L. Salassa, P. J. Sadler, Dalton Trans. (2009) 10690.

[2] D. Barolet, Semin.Cutan. Med. Surg. 27 (2008) 227.

[3] (a) S. W. Magennis, A. Habtemariam, O. Novakova, J. B. Henry, S. Meier, S. Parsons, I. D. H. Oswald, V. Brabec, P. J. Sadler, Inorg. Chem. 46 (2007) 5059; (b) N. J. Farrer, J. A. Woods, L. Salassa, Y. Zhao, K. S. Robinson, G.J. Clarkson, F. S. Mackay, P. J.Sadler, Angew. Chem. Int. Ed 49 (2010) 8905.

[4] (a) Y. K. Yan, M. Melchart, A. Habtemariam, P. J. Sadler, Chem. Commun. (2005) 4764; (b) A. Habtemariam, M. Melchart, R. Fernandez, S. Parsons, I. D. H. Oswald, A. Parkin, F. P. A. Fabbiani, J. E. Davidson, A. Dawson, R. E. Aird, D. I. Jodrell, P. J. Sadler, J. Med. Chem. 49 (2006) 6858; (c) F. Wang, A. Habtemariam, E. P. L. van der Geer, R. Fernandez, M. Melchart, R. J. Deeth, R. Aird, S. Guichard, F. P. A. Fabbiani, P. Lozano-Casal, I. D. H. Oswald, D. I. Jodrell, S. Parsons and P. J. Sadler, Proc. Nat. Sci. USA 102 (2005) 18269.(d) A. M. Pizarro. A. Habtemariam, P.J. Sadler, Topics in Organometallic Chemistry 32 (2010) 21.

[5] (a) S. Betanzos-Lara, L. Salassa, A. Habtemariam, P. J. Sadler, Chem. Commun. (2009) 6622; (b) S. Betanzos-Lara, L. Salassa, A. Habtemariam, O. Nováková, A. M. Pizarro, G. J. Clarkson, B. Liskova, V. Brabec, P. J. Sadler, Organometallics, DOI: 10.1021/om201177y.(c) F. Barragan, P. Lopez-Senín, L.Salassa, S.Betanzos-Lara, A.Habtemariam, V. Moreno, P. J. Sadler, V. Marchan, J. Am. Chem. Soc. 133 (2011), 14098.

[6] M. J. Frisch, G. W. Trucks, H. B. Schlegel, G. E. Scuseria, M. A. Robb, J. R. Cheeseman, J. A. J. Montgomery, T. Vreven, K. N. Kudin, J. Tomasi, V. Barone, B. Mennucci, M. Cossi, G. Scalmani, N. Rega, G. A. Pettersson, H. Nakatsuji, M. Hada, M. Ehara, K. Toyota, R. Fukuda, J. Hasegawa, M. Ishida, T. Nakajima, Y. Honda, O. Kitao, H. Nakai, M. Klene, X. Li, J. E. Knox, H. P. Hratchian, J. B. Cross, V. Bakken, C. Adamo, J. Jaramillo, R. Gomperts, R. E. Stratmann, O. Yazyev, A. J. Austin, R. Cammi, C. Pomelli, J. W. Ochterski, P. Y. Ayala, K. Morokuma, G. A. Voth, P. Salvador, J. J. Dannenberg, V. G. Zakrzewski, S. Dapprich, A. D. Daniels, M. C. Strain, O. Farkas, D. K. Malick, A. D. Rabuck, K. Raghavachari, J. B. Foresman, J. V. Ortiz, Q. Cui, A. G. Baboul, S. Clifford, J. Cioslowski, B. B. Stefanov, G. Liu, A. Liashenko, P. Piskorz, I. Komaromi, R. L. Martin, D. L. Fox, T. Keith, M. A. Al-Laham, C. Y. Peng, A. Nanayakkara, M. Challocombe, P. M. W. Gill, B. Johnson, W. Chen, M. W. Wong, C. Gonzalez and J. A. Pople, Gaussian 03, (Revision D 0.1); Gaussian Inc.: Wallingford CT, (2004).

[7] (a) C. Adamo, V. Barone, J. Chem. Phys. 110 (1999) 6158; (b) C. Adamo, G. E. Scuseria, V. Barone, J. Chem. Phys. 11 (1999) 2889. 
[8] P. J. Hay, W. R. Wadt, J. Chem. Phys. 82(1985) 270.

[9] A. D. McLean, G. S. Chandler, J. Chem. Phys. 72 (1980) 5639.

[10] M. Cossi, N. Rega, G. Scalmani, V. Barone, J. Comput. Chem. 24 (2003) 669.

[11] (a) M. E. Casida, C. Jamorski, K. C. Casida, D. R. Salahub, J. Chem. Phys.108 (1998) 4439; (b) R. E. Stratmann, G. E. Scuseria, M. J. Frisch, J. Chem. Phys. 109 (1998) 8218.

[12] W. R. Browne, N. M. O'Boyle, J. J. McGarvey, J. G. Vos, Chem. Soc. Rev. 34 (2005) 641.

[13] N. M. O'Boyle, J. G. Vos, GaussSum, Dublin City University.Available at http://gausssum. sourceforge.net. (2005).

[14] E. F.Pettersen, T. D. Goddard, C. C. Huang, G. S. Couch, D. M. Greenblatt, E. C. Meng, T. E. Ferrin, J. Comput. Chem. 25 (2004) 1605.

[15] B. Serli, E. Zangrando, T. Gianferrara, C. Scolaro, P. J. Dyson, A. Bergamo, E. Alessio, Eur. J. Inorg. Chem. (2005) 3423.

[16] I. Bratsos, E. Mitri, F. Ravalico, E. Zangrando, T. Gianferrara, A. Bergamo, E. Alessio, Dalton Trans. (2012) DOI: 10.1039/c2dt30654a.

[17] (a) G. M. Sheldrick, ActaCryst.A46 (1990) 467; (b) G. M. Sheldrick, ActaCryst.A64 (2008) 12.

[18] (a) L. Salassa, C. Garino, G. Salassa, R. Gobetto, C. Nervi, J. Am. Chem. Soc. 130 (2008) 9590; (b) L. Salassa, C. Garino, G. Salassa, C. Nervi, R. Gobetto, C. Lamberti, D. Gianolio, R. Bizzarri, P. J. Sadler, Inorg. Chem. 48 (2009) 1469.

[19] A. Meister, M. E. Anderson, Annu. Rev. Biochem. 52 (1983) 711.

[20] Reedijk, J. Chem. Rev. 99 (1999) 2499.

[21] L. Salassa, H. I. A. Phillips, P. J. Sadler, Phys. Chem. Chem. Phys. 11 (2009) 10311.

[22] A. Jr Vlček, S. Záliš, Coord. Chem. Rev. 251 (2007) 258.

[23] S. Roche, H. Adams, S. E. Spey, J. A. Thomas, Inorg.Chem. 39 (2000) 2385. 